\title{
Two soulmates !!!
}

\section{Selma El Kadiri, Hanane Bay Bay, Rhizlane Chaoui, Zakia Douhi, Sara Elloudi, Fatima Zahra Mernissi}

\author{
Department of Dermatology and Venerology, University Hospital Hassan II, Fez, Morocco
}

Corresponding author: Dr. Selma El Kadiri, E-mail: elkadiri-s@hotmail.com

Sir,

A woman in her 20s was referred to our consultation with a diagnosis of genital warts treated with two sessions of $50 \%$ trichloroacetic acid application. She didn't report any extramarital sexual intercourse. She also reported similar lesions in her partner. On clinical examination, warty lesions were noted at the vestibule. They were soft, pinkish mucosal projections with regular distribution on the vestibule (Fig. 1). Dermoscopy showed linear, pinkish papillae over the vulvar vestibule and irregular linear vascular channels were observed in the transparent core of papillae (Fig. 2). Histological examination didn't show any koilocyte changes excluding the diagnosis of genital condyloma. On clinical examination of her husband, we found dome-shaped, whitish and small papules circumferentially at the corona compatible with the diagnosis of pearly penile papules (Fig. 3). We reassured the couple and no treatment was required.

Vestibular papillomatosis or physiologic papillomatosis is a common and normal finding of no significance around the introitus on external examination. Their appearance may be confused with an HPV-related lesion and require a biopsy to condyloma acuminatum [1]. Clinically, it manifests with small, soft, and arranged in a linear distribution, fingerlike papillary projections around the vaginal opening. They can be sometimes painful or pruriginous [2]. The exact etiology is unknown, they are particularly common in pregnancy but they do not appear to be associated with HPV infection [1]. Dermoscopy showed pinkish soft lesions arising from a solitary base with irregular vascular channels in the transparent core of cylindrical papillae [2]. The penile pearly papules are considered to be the male equivalent of vestibular papillomatosis. They are also called hirsutoid papillomas and are frequently mistaken for warts and Tyson or ectopic sebaceous glands. These lesions may regress with circumcision and old age [3]. We named our patient's soulmates because they have the same physiological condition.

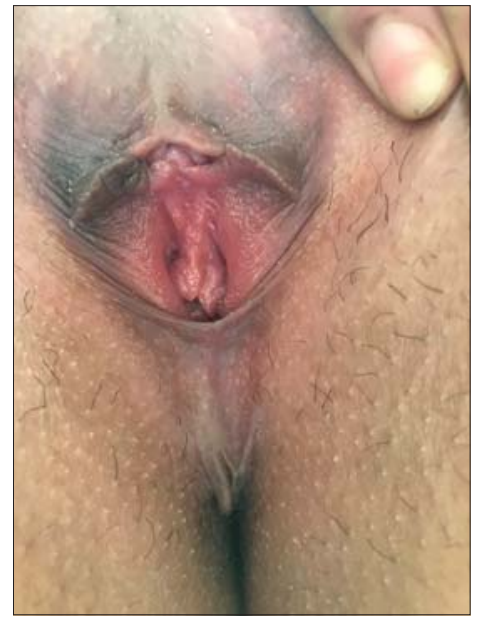

Figure1: Vestibular papillomatosis: numerous pale papillomata in the vestibule and on the labia minora.

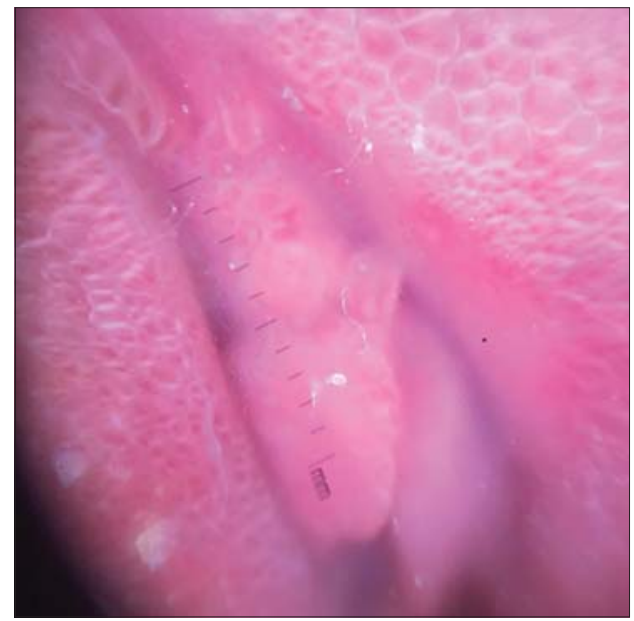

Figure 2: Dermoscopy showing pinkish soft lesions arinsing from solitary base.

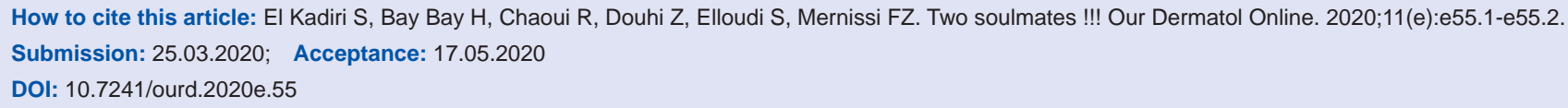


www.odermatol.com

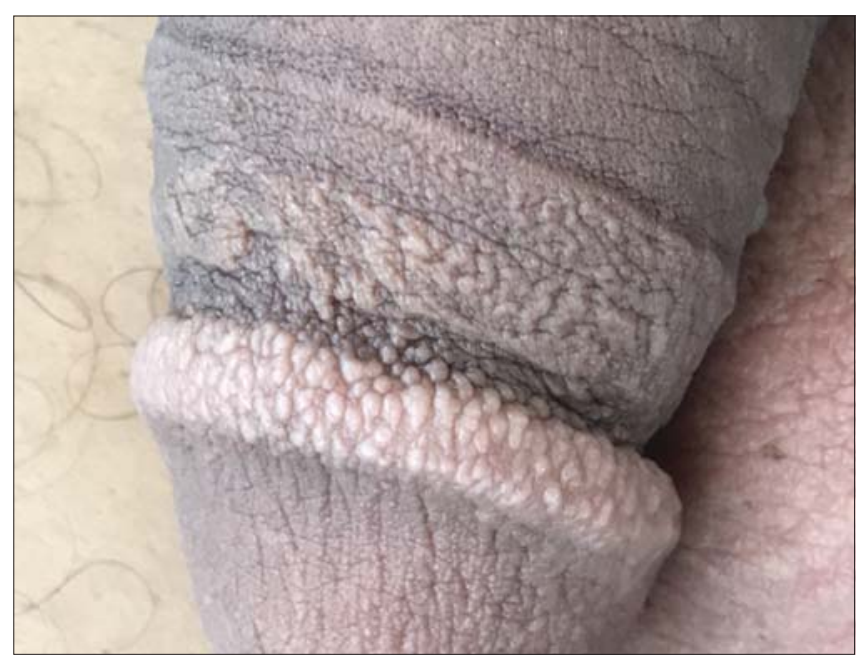

Figure 3: Pearly penile papules.

\section{Consent}

The examination of the patient was conducted according to the Declaration of Helsinki principles.
The authors certify that they have obtained all appropriate patient consent forms. In the form the patient(s) has/have given his/her/ their consent for his/her/their images and other clinical information to be reported in the journal. The patients understand that their names and initials will not be published and due efforts will be made to conceal their identity, but anonymity cannot be guaranteed.

\section{REFERENCES}

1. Razmi T. Vestibular papillomatosis: a normal variation commonly misdiagnosed as genital condylomata. Am J Obstet Gynecol. 2019;220:403.

2. Ozkur E. Vestibular Papillomatosis: An Important Differential Diagnosis of Vulvar Papillomas. Dermatol Online J. 2016;22:pii: 13030/qt7933q377.

3. Agrawal SK, Bhattacharya SN, Singh N. Pearly penile papules: a review. Int J Dermatol. 2004;43:199-201.

Copyright by Selma El Kadiri, et al. This is an open-access article distributed under the terms of the Creative Commons Attribution License, which permits unrestricted use, distribution, and reproduction in any medium, provided the original author and source are credited.

Source of Support: Nil, Conflict of Interest: None declared. 